\title{
Determination of Internal Pressure in a Shell and Tube Type of Heat Exchanger by Using IBR and ASME Codes
}

\author{
R. V. Patil ${ }^{1}$, S. S. Bhutada ${ }^{2}$, N. R. Katruwar ${ }^{2}$, R. R. Rai ${ }^{2}$, K. N. Dhumke ${ }^{2}$ \\ ${ }^{1}$ (Department of Mechanical Engineering, Sinhgad institute of technology and science, Pune, India) \\ ${ }_{2}^{2}$ (Department of Mechanical Engineering, Sinhgad Institute of Technology and science, Pune, India)
}

\begin{abstract}
The shell and tube type heat exchanger is a non-fired pressure system consisting of two different pressure chambers such as shell chamber and tube chamber. It is separated by the internal tube wall, two media flow past each other with such alignment that, if there is a heat difference, they will mutually exchange heat without mixing in the process. While there is an enormous variety of specific design features that can be used in shell and tube exchangers, the number of basic components is relatively small. This paper aims at performing a comprehensive comparison of the design outputs by IBR and ASME codes of critical components of a shell and tube type heat exchanger in an attempt to show the redundancy in designing the components using both these codes simultaneously.
\end{abstract}

Keywords: Shell and tube type heat exchanger, IBR, ASME, tube sheet, steam drum.

\section{Introduction}

Heat exchangers are devices used to transfer heat between two or more fluid streams at different temperatures. Heat exchangers find widespread use in power generation, chemical processing, electronics cooling, air-conditioning, refrigeration, and automotive applications. A shell and tube heat exchanger is a cylindrical vessel housing a set of tubes called the tube bundle, containing fluid at some temperature and immersed in another fluid at a different temperature. The transfer of heat occurs between the fluid flowing over the tubes and the fluid flowing inside the tubes. The fluid flow inside the tubes is said to be "tube side" and the fluid flow external to the tube bundle is said to be "shell side" F. Vera-García et al [1] have proposed a simplified model for the study of shell-and-tubes heat exchangers (HXs). The developed model aims to agree with the HXs when they are working as condensers or evaporators. Despite its simplicity, the model proves to be useful to the pre-designment and correct selection of shell-and-tubes HXs working at full and complex systems. S. V. Karmare et al. [3] have performed a comparison of the tube sheet stress pattern and thickness obtained with different Finite element analysis of the tube sheet. For stress distribution and tube sheet thickness which also come under the scope of their paper whose results were compared with those previously obtained from design with different standard codes. This study has selected the best configuration of the tube sheet for the design. G. Manenti et al .[2] state that a waste heat recovery boiler is designed to oxidize acid gases by air because of several oxidation reactions are reversible, as the gas is cooled in the boiler recombination reactions occur, modifying the heat exchange and gas composition. This may have a significant effect on the design of the waste heat boiler and downstream Claus reactors. In their study, the design of thermal reactor and waste heat boiler system is proposed by adopting a common model.

\subsection{American Society of Mechanical Engineers (ASME)}

The international boiler and pressure vessel code established rules of safety relating only to pressure integrity governing the design, fabrication and inspection of boilers and pressure vessels, and nuclear power plant vessels during construction. The objective of these rules is to provide a margin for deterioration in service. Advancements in design and material and the evidence of experience are constantly being added.

\subsection{Indian Boiler Regulations (IBR)}

Indian Boiler Regulations are the standards in respect of materials, design and construction inspection and resting of boilers and boiler components for compliance by the manufacturers and users of boilers in the country. These regulations are being updated regularly by amending them in line with the fast changes in boiler technology by the central boilers board. The object therefore of the present legislation is [5].

- To secure uniformity throughout India in all technical matter connected with boiler regulation.

- To insist on the regulation and inspection of all boilers throughout India 


\section{Major Components of Shell and Tube Type of Heat Exchanger}

The shell is the container which provides space for the exchange of heat between the two media. It houses assembly of tubes (Tube bundle) inside and remaining space for shell-side fluid. The shell has nozzles at its periphery for inlet and outlet for steam and water. The tube bundle has a large number of tubes which are decided on the basis of the capacity and purpose of the boiler for which it is designed. In a fire tube heat exchanger the hot flue gases pass through the tubes and have water or any other heat transferring fluid on the periphery. Tubes span across the length of boiler shell from the furnace side tube sheet to the channel side tube sheet. Tubes are welded to tube sheet on both the ends.Tubesheet is thick plate with multiple holes drilled in it. It has same number of holes as that of number of tubes in tube bundle. Steam drum is an external attachment which is connected to the shell through risers and down comer pipes. It holds feed water and steam generated in the process. It is a major component as it separates steam from water. Boiler shell, tube, tube sheet and steam drum are the major components of shell and tube type heat exchanger.

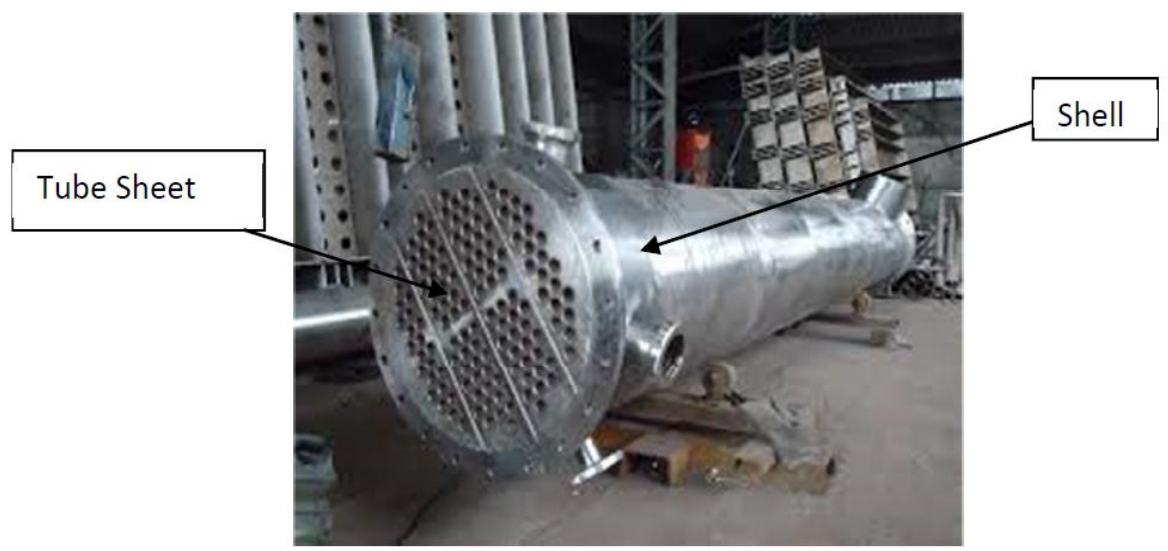

Fig 1. Assembly of shell and tube type of heat exchanger

\subsection{Boiler Shell}

The shell is simply the container for the shell-side fluid, and the nozzles are the inlet and exit ports. The shell normally has a circular cross section and is commonly made by rolling a metal plate of the appropriate dimensions into a cylinder and welding the longitudinal joint "rolled shells". Small diameter shells up to around 24 inches in diameter can be made by cutting pipe of the desired diameter to the correct length ("pipeshells"). The roundness of the shell is important in fixing the maximum diameter of the baffles that can be inserted and therefore the effect of shell-to-shell baffle leakage. Pipe shells are more nearly round than rolled shells unless particular care is taken in rolling. In large exchangers, the shell is made out of low carbon steel wherever possible for reasons of economy, though other alloys can be and are used when corrosion or high temperature strength demands must be met.

\subsection{Tube Sheet}

Tube sheet is an important part of shell and tube type heat exchanger, which separates the tube side fluid and shell side fluid. Proper design of tube sheet is important for safe and reliable operation of heat exchanger, especially steam generators. They are generally circular with uniform pattern of holes. The study of the stresses developed in the tube sheet is of importance in order to select the tube sheet thickness. The tubes are held in place by being inserted into holes in the tube sheet and there either expanded into grooves cut into the holes or welded to be tube sheet where the tube protrudes from the surface.

\subsubsection{Tube Sheet Layout}

Tube pitch is defined as the shortest distance between two adjacent tubes. In our work we employ the minimum recommended tube pitch, because it leads to the smallest shell diameter for a given number of tubes. However, in exceptional circumstances, the tube pitch may be increased to a higher value, for example, to reduce shell side pressure drop. This is particularly true in the case of a cross-flow shell. 


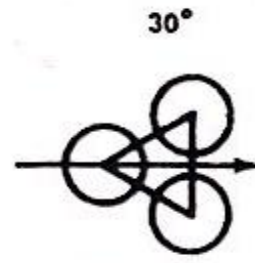

Triangular

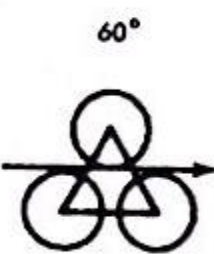

Rotated

Triangular

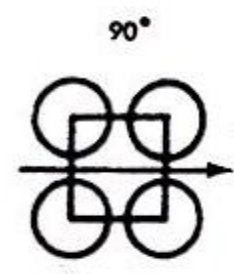

Square

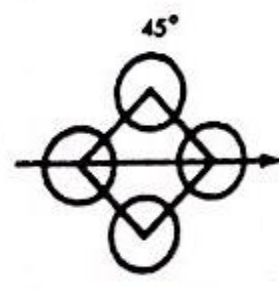

Rotated

Fig.2 Schematic representation of tube sheet layout

\subsection{Tubes}

The tubes are the basic component of the shell and tube exchanger, providing the heat transfer surface between one fluid flowing inside the tube and the other fluid flowing across the outside of the tubes. The tubes may be seamless or welded and most commonly made of copper or steel alloys. Other alloys of nickel, titanium, or aluminium may also be required for specific applications. The tubes may be either bare or with extended or enhanced surfaces on the outside. Extended or enhanced surface tubes are used when one fluid has a substantially lower heat transfer coefficient than the other fluid. Extended surfaces, (finned tubes) provide two or four times as much heat transfer area on the outside as the corresponding bare tube, and this area ratio helps to outside heat transfer co-efficient. More recent developments are: a corrugated tube which has both inside and outside heat transfer enhancement, a finned tube which integral inside tabulators as well as extended outside surface, and tubing which has outside surfaces designed to promote nucleate boiling.[9]

\subsection{Steam Drum}

A steam drum is a pressure chamber of a steam boiler located at the upper extremity of steam boiler circulatory system. It is a reservoir of water/steam at the top end of the water tubes. The steam drum stores the steam generated in the water tubes and acts as a phase-separator for the steam/water mixture. Steam is separated from the water and then discharged at a position above the water level maintained there. Thermodynamically a steam drum is merely a surge tank in the circulation system to which the following parts are connected: Economizer outlet and super heater inlet pipes on one side, down comers and risers on the other side.

\section{Internal pressure by IBR \& ASME Codes}

By using codes, we are calculating internal pressure for major component used in shell and tube type of heat exchanger.

\subsection{IBR 270 for internal pressure in Boiler shell [5]}

- $\quad$ Selected design Parameters:

\begin{tabular}{|l|c|c|}
\hline \multicolumn{1}{|c|}{ Parameters } & Nomenclature & Range \\
\hline Design pressure & $\mathrm{P}$ & $54.72 \mathrm{kgf} / \mathrm{cm}^{2}=5.36 \mathrm{MPa}$ \\
\hline Design metal temperature & $\mathrm{T}$ & $272{ }^{\circ} \mathrm{C}$ \\
\hline Material specification & - & SA 516 GR 70 \\
\hline Allowable stress & $\mathrm{F}$ & $1398.03 \mathrm{kgf} / \mathrm{cm}^{2}=137.1 \mathrm{MPa}$ \\
\hline Thickness of plate selected & $\mathrm{T}$ & $90 \mathrm{~mm}$ \\
\hline Internal diameter (corroded condition) & $\mathrm{D}$ & $3911.00 \mathrm{~mm}$ \\
\hline Corrosion allowance & $\mathrm{C}$ & $3 \mathrm{~mm}$ \\
\hline Minimum ligament efficiency & $\mathrm{E}$ & 1.00 \\
\hline
\end{tabular}

Minimum required thickness of an unpierced drum shell $\mathrm{t}_{\min }=\frac{p \times d}{2 \times f \times E-P}$

$$
\mathrm{t}_{\min }=\frac{(54.72 \times 3911)}{2 \times 1398.03 \times 1-54.72}
$$

Minimum required thickness of an unpierced drum shellt $\min =78.06 \mathrm{~mm}$

\subsection{ASME Code for Internal Pressure in Boiler shell [6]}

- Selected design Parameters:

\begin{tabular}{|l|c|c|}
\hline \multicolumn{1}{|c|}{ Parameters } & Nomenclature & Range \\
\hline Temperature coefficient for ferritic steel below $480^{\circ} \mathrm{C}$ & $\mathrm{Y}$ & 0.4 \\
\hline Minimum allowance for threading and structural stability & $\mathrm{C}$ & $0 \mathrm{~mm}$ \\
\hline
\end{tabular}

Minimum required drum shell thickness: $\mathrm{t}_{\min }=\frac{P \times D}{2 S E+2 y P}+C+C_{A}$ 
Determination of Internal Pressure in a Shell and Tube Type of Heat Exchanger by Using IBR.....

$$
\mathrm{t}_{\min }=\frac{5.36 \times 3911}{2 \times 137.1 \times 1+2 \times 0.4 \times 5.36}+0+3
$$

Minimum required drum shell thickness: $t_{\min }=\mathbf{7 8 . 2 7} \mathbf{m m}$

\subsection{IBR 580 for Internal Pressure in Tube sheet [5]}

- $\quad$ Selected design Parameters:

\begin{tabular}{|l|c|l|}
\hline \multicolumn{1}{|c|}{ Parameters } & Nomenclature & \multicolumn{1}{c|}{ Range } \\
\hline Material selected & - & SA 516 GR 70 \\
\hline Thickness selected & T & $45 \mathrm{~mm}$ \\
\hline Maximum tube hole diameter & D & $115.3 \mathrm{~mm}$ \\
\hline
\end{tabular}

\subsubsection{Pitch of tubes}

Generally the spacing of tube holes shall be such that the minimum width in inches of any ligament between the tube holes shall be not less than:-

$$
\left[\frac{D}{8}+\frac{1}{2}\right]=1.0674 "
$$

Ligament provided $=$ Pitch - tube hole diameter

$$
\text { Ligament }=27.113 \mathrm{~mm}
$$

$$
\begin{aligned}
& =149-115.3 \\
& =33.7 \mathrm{~mm}
\end{aligned}
$$

\subsubsection{Cross sectional area of tube plate at tube hole}

Minimum cross section of tube required $=(0.17 \mathrm{D}+0.025)^{\prime \prime 2}$

Cross section provided $=$ Ligament $\times$ Thickness

$$
=0.7968^{\prime \prime 2}=513.99 \mathrm{~mm}^{2}
$$

$$
=33.70 \times 45=1516.5 \mathrm{~mm}^{2}
$$

\begin{tabular}{|c|c|c|}
\hline Parameters & Nomenclature & Range \\
\hline $\begin{array}{l}\text { Maximum pitch measured between straight lines passing through } \\
\text { the centres of stay bolts }\end{array}$ & $\mathrm{P}$ & $149 \mathrm{~mm}$ \\
\hline Maximum allowable working pressure & $\mathrm{P}$ & $5.36 \mathrm{~mm}$ \\
\hline Maximum allowable stress & $\mathrm{S}$ & $137.1 \mathrm{MPa}$ \\
\hline For welded stays & $\mathrm{C}$ & 2.2 \\
\hline Corrosion allowance for tube sheet & $\mathrm{CA}$ & $6 \mathrm{~mm}$ \\
\hline
\end{tabular}

Minimum thickness is given by $=(0.125 \mathrm{D}+0.2) "$

$$
=0.767^{\prime \prime}
$$

Minimum thickness of tube sheet $=19.49 \mathrm{~mm}$

\subsection{ASME Code for Internal Pressure in Tube sheet [6]}

- Selected design Parameters:

Maximum required tube sheet thickness: $t=\sqrt{\frac{P}{C S}\left(p^{2}+\frac{\pi d^{2}}{4}\right)}+C A$

$$
t=\sqrt{\frac{5.36}{2.2 \times 137.1}\left(149^{2}+\frac{\pi \times 115.3^{2}}{4}\right)}+6
$$

Maximum required tube sheet thickness $\mathrm{t}=20.46 \mathrm{~mm}$

\subsection{IBR 579for External Pressure in Tube [5]}

- Selected design Parameters:

\begin{tabular}{|l|c|l|}
\hline \multicolumn{1}{|c|}{ Parameters } & Nomenclature & \multicolumn{1}{c|}{ Range } \\
\hline Material selected & - & SA 210 GR A1 \\
\hline Thickness of tube selected & T & $6.6 \mathrm{~mm}$ \\
\hline External design pressure & WP & $54.72 \mathrm{~kg} / \mathrm{cm}^{2}$ \\
\hline Outside diameter of tube & D & $114.3 \mathrm{~mm}$ \\
\hline Corrosion allowance & C & $0.0 \mathrm{~mm}$ \\
\hline Allowable stress at $343^{0} \mathrm{C}$ & F & $1196.13 \mathrm{~kg} / \mathrm{cm}^{2}$ \\
\hline
\end{tabular}

Maximum allowable external pressure $P=\frac{1.6 f \times t}{D}$

Maximum allowable external pressure $P=10.84 \mathrm{MPa}$ 
Determination of Internal Pressure in a Shell and Tube Type of Heat Exchanger by Using IBR.....

\subsection{ASME Code for External Pressure in Tube [6]}

- Selected Design Parameters:

\begin{tabular}{|l|c|c|}
\hline \multicolumn{1}{|c|}{ Parameters } & Nomenclature & Range \\
\hline External design pressure & Pexternal & $5.36 \mathrm{MPa}$ \\
\hline Design metal temperature & $\mathrm{T}$ & $272^{\circ} \mathrm{C}$ \\
\hline Tube length & $\mathrm{L}$ & 6096 \\
\hline
\end{tabular}

Here,

$$
\begin{aligned}
\mathrm{L} / \mathrm{D}_{\mathrm{o}} & =6096 / 114.3 \\
& =53.33 \\
\mathrm{D}_{\mathrm{o}} / \mathrm{t}= & 114.3 / 6.6 \\
& =17.31
\end{aligned}
$$

Factor $\mathrm{A}=0.004$

(ASME Section II, Part D, Subpart 3)From figure G, (Page 794)

Using the above value of $\mathrm{A}$ and for temperature $343^{\circ} \mathrm{C}$.

$$
\mathrm{B}=100 \mathrm{MPa} \quad \text { Referring to figure CSII (ASME Section II, Part D) }
$$

Maximum allowable external working pressure $(\mathrm{Pa}) \ldots$

$$
\begin{aligned}
& =\frac{4 B}{3\left(\frac{D_{0}}{t}\right)} \\
& =\frac{4 \times 100}{3 \times 17.31}
\end{aligned}
$$

Maximum allowable external working pressure $=7.7 \mathrm{MPa}$

\subsection{IBR 270 for Internal Pressure in Steam drum [5]}

- Selected design Parameters

\begin{tabular}{|l|c|c|}
\hline \multicolumn{1}{|c|}{ Parameters } & Nomenclature & Range \\
\hline Design pressure & $\mathrm{P}$ & $54.06 \mathrm{kgf} / \mathrm{cm}^{2}$ \\
\hline Design metal temperature & $\mathrm{T}$ & $\begin{array}{c}\text { Shell side } 272{ }^{\circ} \mathrm{C} \\
\text { Tube Side } 343{ }^{\circ} \mathrm{C}\end{array}$ \\
\hline Material specification & - & SA $516 \mathrm{GR} 70$ \\
\hline Allowable stress & $\mathrm{F}$ & $1398.03 \mathrm{kgf} / \mathrm{cm}^{2}$ \\
\hline Thickness of plate selected & $\mathrm{T}$ & $63 \mathrm{~mm}$ \\
\hline Internal diameter (corroded condition) & $\mathrm{D}$ & $2606.00 \mathrm{~mm}$ \\
\hline Corrosion allowance & $\mathrm{C}$ & $3 \mathrm{~mm}$ \\
\hline Minimum ligament efficiency & $\mathrm{E}$ & 1.00 \\
\hline
\end{tabular}

Min required thickness of an unpierced drum shell $\mathrm{t}_{\min } \frac{P \times d}{2 \times f \times E-P}$

$$
\mathrm{t}_{\min }=\frac{54.06 \times 2606}{2 \times 1398.03 \times 1-54.06}
$$

Min required thickness of an unpierced drum shell $t_{\min =} 51.38 \mathrm{~mm}$

3.8 ASME Code for Internal Pressure in Steam drum [6]

- Selected design Parameters:

\begin{tabular}{|l|c|c|}
\hline \multicolumn{1}{|c|}{ Parameters } & Nomenclature & Range \\
\hline Design Pressure & $\mathrm{P}$ & $5.301 \mathrm{MPa}$ \\
\hline External design pressure & $\mathrm{P}_{\mathrm{ext}}$ & $0.11 \mathrm{MPa}$ \\
\hline Drum outside diameter & $\mathrm{D}$ & $2606 \mathrm{~mm}$ \\
\hline Temperature coefficient (for ferritic steel below $480^{\circ} \mathrm{C}$ ) & $\mathrm{Y}$ & 0.4 \\
\hline Minimum allowance for threading and structural stability & $\mathrm{C}$ & $0 \mathrm{~mm}$ \\
\hline
\end{tabular}

$$
\text { Minimum required drum shell thickness: } \begin{aligned}
t & =\frac{P \times D}{2 S E+2 y P}+C+C_{A} \\
& =\frac{5.301 \times 2606}{2 \times 137.1 \times 1+2 \times 0.4 \times 5.301}+0+3
\end{aligned}
$$

Minimum required drum shell thickness $=\mathbf{5 2 . 6 1} \mathbf{~ m m}$ 


\section{Results}

The following result shows the calculated values of internal pressure by using IBR and ASME codes in following components.

\begin{tabular}{|c|c|c|}
\hline Components & IBR Code & ASME Code \\
\hline Boiler shell & $78.06 \mathrm{~mm}$ & $78.27 \mathrm{~mm}$ \\
\hline Tube sheet & $19.49 \mathrm{~mm}$ & $20.46 \mathrm{~mm}$ \\
\hline Tubes & $10.84 \mathrm{MPa}$ & $7.70 \mathrm{MPa}$ \\
\hline Steam drum & $51.38 \mathrm{~mm}$ & $52.61 \mathrm{~mm}$ \\
\hline
\end{tabular}

\section{Conclusion}

A comprehensive study of the IBR and ASME codes for design of boiler shell, tube sheet, steam drum and tubes of a shell and tube type heat exchanger was performed to arrive at the following conclusions.

- Although the approach to the design of the components may differ their results show negligible deviation. This is primarily due to the widespread understanding present today in regard to the material properties and their behaviour when subjected to different type of stresses.

- Today even though the buyers stipulate that the components be designed in accordance with both IBR and ASME codes it has been proved that such a practice is redundant and therefore may be discontinued.

- The above results provide a sample case containing a few critical components but the results can be extrapolated to include virtually all other auxiliary components.

- Conventionally there existed a multitude of codes available to regulate boiler safety owing to the limitation of information available but in contemporary times this conventional system is obsolete and a strong need arises for a universal governing standard.

\section{References}

[1]. F. Vera-García et al, A simplified model for shell-and-tubes heat exchangers: Practical application, Engineering, Volume, July 2010, Pages 1231-1241.

[2]. G. Manenti et al, Design of SRU thermal reactor and waste heat boiler considering recombination reactions. 20th International Congress of Chemical and Process Engineering CHISA 2012, 25 - 29 August 2012, Prague, Czech Republic, Proc. Engineering 42 (2012) $376-383$.

[3]. A. V. Hantodkar, "Design and Analysis for Tube Sheet of Shell and Tube Type Heat Exchanger Using Finite Element Technique". ASME, paper no G201

[4]. F. Osweiller, "Tube sheet Heat Exchangers: Analysis And Comparison Of TEMA Codap And ASME Methods", Proceedings of the Sixth International Conference Held in Beijing, People's Republic of China, 11-15 September 1988-1989, Pages 385-400.

\section{Books}

[5]. IBR 1950 and latest amendments.

[6]. ASME Codes 2013, ASME - Section VIII- Division 1, ASME section I.

[7]. Tubular Exchanger Manufacturers Association, "Standards of the Tubular Exchanger Manufacturers Association,"

[8]. Process equipment design- Brownell and Young.

[9]. Wolverine tube heat transfer data book. 